\title{
SEGURANÇA CIDADÃ: FORMAS DE ENVOLVIMENTO E PROPENSÃO DO CIDADÃO À COPRODUÇÃO DE SEGURANÇA PÚBLICA NO DISTRITO FEDERAL
}

\author{
CITIZEN SECURITY: FORMS OF CITIZEN INVOLVEMENT \\ AND PROPENSITY TO CO-PRODUCING PUBLIC SECURITY IN \\ THE FEDERAL DISTRICT
}

\section{SEGURIDAD CIUDADANA: FORMAS DE IMPLICACIÓN Y PROPENSIÓN DEL CIUDADANO A LA COPRODUCCIÓN DE SEGURIDAD PUBLICA EN EL DISTRITO FEDERAL}

Isabela Miranda Martins

Mestre em Administração de Empresas pela Universidade de Brasília

isa.mmartins.im@gmail.com

\author{
Josivania Silva Farias \\ Professora em Administração da Universidade de \\ Brasília \\ Doutora em Administração em Administração pela \\ Universidade de Brasília \\ josivania@unb.br
}

Lucio Alves Angelo Junior

Mestrando em Administração na Universidade de Brasília

luciojr.prof@gmail.com

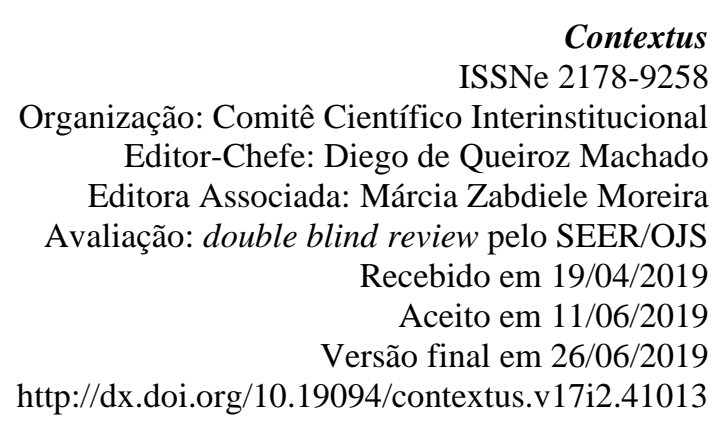

Contextus

ISSNe 2178-9258

Organização: Comitê Científico Interinstitucional Editor-Chefe: Diego de Queiroz Machado

Editora Associada: Márcia Zabdiele Moreira

cebido em 19/04/2019

Versão final em 26/06/2019

http://dx.doi.org/10.19094/contextus.v17i2.41013

\begin{abstract}
RESUMO
Este estudo identificou formas de envolvimento do cidadão na segurança pública, considerando as atividades desempenhadas pelos cidadãos e a propensão para a coprodução de segurança no Distrito Federal. Em estudo qualitativo-descritivo, foram realizadas 82 entrevistas semiestruturadas com cidadãos residentes no Distrito Federal, sendo 22 engajados em mecanismos formais de coprodução e 60 não engajados nesses mecanismos. Os dados foram analisados por meio de análise de conteúdo, utilizando a técnica de saturação teórica. Observou-se que os sujeitos do estudo contribuem com a segurança pública por meio de ações de natureza preventiva e repressiva, sendo identificadas as formas de coprodução de informação, política, social, econômica, preventiva e repressiva. Quanto à propensão a coproduzir, constataram-se sete aspectos que tornariam os cidadãos mais propensos a coproduzir, ampliando a compreensão acerca do fenômeno da coprodução da segurança pública.

Palavras-chave: segurança cidadã; coprodução de serviços públicos; formas de coprodução; segurança pública; cidadão.
\end{abstract}

\begin{abstract}
This study identified the forms of citizen involvement in public security, considering the activities performed by citizens and their propensity to co-produce public safety in the Federal District. In a qualitative-descriptive study, 82 semi-structured interviews were carried out with 22 engaged citizens and 60 non-engaged in formal safety coproduction mechanisms. In order to analyze data, a content analysis was carried out using theoretical saturation. It is seen that the citizens interviewed in the study contribute to security through preventive and repressive actions and the forms of co-production identified were informational, political, economic, social, preventive and repressive. Seven categories were identified that would make uninvolved citizens more likely to contribute to security, expanding the understanding about the phenomenon of public safety coproduction.
\end{abstract}

Keywords: citizen security; public service co-production; forms of co-production; public safety; citizen. 


\section{RESUMEN}

Esta investigación identificó formas de involucración del ciudadano en la seguridad pública, considerando las actividades desempeñadas por los ciudadanos y la propensión para la coproducción de seguridad en el Distrito Federal. En un estudio cualitativo-descriptivo se realizaron 82 entrevistas semiestructuradas con ciudadanos residentes en el Distrito Federal, siendo 22 envueltos en mecanismos formales de coproducción y 60 no involucrados en esos mecanismos. Los datos fueron analizados por medio de análisis de contenido, utilizando la técnica de saturación teórica. Se observó que los participantes del estudio contribuyen con la seguridad pública por medio de acciones de naturaleza preventiva y represiva, siendo identificadas las formas de coproducción de información, política, social, económica, preventiva y represiva. En cuanto a la propensión a coproducir, se constataron siete aspectos que harían a los ciudadanos más propensos a coproducir, ampliando la comprensión acerca del fenómeno de la coproducción de la seguridad pública.

Palabras clave: seguridad ciudadana; coproducción de servicios públicos; formas de coproducción; seguridad pública; ciudadano.

\section{INTRODUÇÃO}

Desde a década de 1970 a coprodução é estudada como o processo de envolvimento ativo do usuário na produção de bens ou serviços (GERSUNY; ROSENGREN, 1973; OSTROM et al., 1978; PERCY, 1978), explorando-se na literatura as formas pelas quais os usuários contribuem, como por exemplo, individualmente, em grupos ou coletivamente (BRUDNEY; ENGLAND, 1983), o tipo de atividade desempenhada pelo usuário (BOVAIRD; LOEFFLER, 2012; NABATCHI; SANCINO; SICILIA, 2017), a motivação e propensão do indivíduo para coproduzir (ETGAR, 2008; ALFORD; YATES, 2015), entre outros aspectos relevantes para se compreender de que modo ocorre a participação do usuário na produção de bens ou serviços. Assim, a coprodução passou a ser estudada no âmbito dos serviços públicos e bens públicos, sendo realizados estudos sobre o envolvimento dos cidadãos na prestação de serviços imprescindíveis ao bem-estar social (WHITAKER, 1980). Loeffler et al. (2008) e Alford e Yates (2015) analisaram, por exemplo, os níveis de coprodução apresentados por cidadãos europeus e australianos respectivamente, comparandose os níveis de coprodução em serviços relacionados ao meio ambiente, à saúde e à segurança pública.

A importância do envolvimento do usuário no desenvolvimento e melhoria de serviços ocasionou o aumento do interesse de se investigar o papel do cidadão como influenciador dos processos e resultados das organizações (GERSUNY; ROSENGREN, 1973), bem como os modos pelos quais os cidadãos podem coproduzir, seja por meio de ações coletivas, grupais ou individuais (BRUDNEY; ENGLAND, 1983; WHITAKER, 1980) e a forma pela qual o indivíduo se esforça, como por exemplo, solicitando ou provendo assistência ao governo (WHITAKER, 1980), doando seu tempo, recursos financeiros ou atuando de forma a 
modificar a prestação do serviço (PESTOFF, 2006). Considerando que atualmente alguns governos buscam estabelecer um relacionamento próximo com cidadãos, a coprodução tornase tema pertinente para elucidar e ressignificar a interação entre governo e sociedade. Quanto às formas de envolvimento do cidadão na prestação do serviço, as formas de coprodução apresentadas pelos cidadãos tais como política, econômica, social, de informação, entre outras, ainda necessitam de maior aprofundamento teórico e empírico (PESTOFF, 2006; VERSCHUERE; BRANDSEN; PESTOFF, 2012).

Para Ostrom e Ostrom (1999, p. 20), “a colaboração entre aqueles que fornecem o serviço e os que o utilizam é essencial para que os serviços públicos alcancem os resultados pretendidos", sendo o caso, por exemplo, da segurança da comunidade, que é produzida em um conjunto por policiais, agentes de segurança pública, cidadãos, entre outras instâncias da sociedade. O artigo 144 da Constituição Federal do Brasil apresenta a segurança pública como "dever do Estado, direito e responsabilidade de todos" (BRASIL, 1988). Para Carvalho e Silva (2011, p. 60), "a segurança pública é considerada uma demanda social que necessita de estruturas estatais e demais organizações da sociedade para ser efetivada". Considerando a relevância do envolvimento do cidadão para a promoção da segurança pública, o presente estudo possui como objetivo analisar de que modo ocorre a coprodução da segurança pública no DF, identificando as atividades desempenhadas pelos cidadãos para contribuir com a segurança, as formas de coprodução e a propensão do cidadão para coproduzir segurança no Distrito Federal.

Constatando-se a predominância de estudos estrangeiros na literatura sobre o tema, com pesquisas conduzidas especialmente em países europeus cujas características destoam da realidade de economias emergentes como o Brasil, fez-se necessário um esforço exploratório e descritivo para identificar de que formas o cidadão atua para colaborar com a segurança pública, bem como a sua propensão para coproduzir segurança. Salm e Menegasso (2010, p. 10) salientam que o termo coprodução ainda não é "suficientemente conhecido, embora a coprodução se faça presente em quase todas as atividades da administração pública”. Desse modo, a literatura sobre coprodução encontra ainda muitas limitações (NABATCHI; SANCINO; SICILIA, 2017; VERSCHUERE; BRANDSEN; PESTOFF, 2012), sendo importante a realização de estudos que possam produzir relevantes contribuições, incluindo a busca por novas tipologias de coprodução.

Este artigo divide-se em cinco seções, sendo a primeira esta introdução. Na segunda seção, apresenta-se o referencial teórico, com a evolução do conceito de coprodução e estudos 
sobre a coprodução da segurança. Na terceira seção, citam-se os procedimentos metodológicos adotados na condução da pesquisa. Após a metodologia, apresentam-se os resultados e discussão à luz da literatura. Por último, apresentam-se as conclusões, limitações e contribuições do estudo.

\section{REFERENCIAL TEÓRICO}

Para Gersuny e Rosengren (1973), em uma sociedade voltada para serviços, o usuário transformou-se em mais do que um consumidor, podendo desempenhar um papel-chave na coprodução de serviços. Desde a década de 1970, o termo coprodução vem sendo estudado como estratégia de utilização do esforço empenhado pelo usuário conjuntamente com o provedor para a produção de serviços (PARKS et al, 1981). Para Mattia e Zappellini (2014, p. 574) o conceito de coprodução "se mostra promissor quando se tem em mente a ideia de uma administração pública voltada efetivamente para a satisfação dos desejos e da vontade dos cidadãos”.

\subsection{Coprodução de serviços}

A coprodução passou a ser analisada como sendo, em diversos casos, essencial para a execução e sucesso de programas de governo (WHITAKER, 1980), sendo considerada uma mistura crítica de atividades em que agentes e cidadãos contribuem para a provisão de serviços públicos (BRUDNEY; ENGLAND, 1983). Isso envolveria, segundo Parks et al. (1981), ações complementares aos esforços de produção dos provedores de bens ou serviços, fazendo com que os indivíduos desempenhassem o papel de produtores e usuários concomitantemente. O Quadro 1 expõe definições de coprodução propostas na literatura, apresentando uma evolução dos conceitos.

Quadro 1 - Evolução dos conceitos de coprodução

\begin{tabular}{|l|l|}
\hline Referência & Definição \\
\hline $\begin{array}{l}\text { Levine e Fisher (1984, } \\
\text { p. 181) }\end{array}$ & $\begin{array}{l}\text { "A prestação conjunta de serviços públicos por agências públicas e consumidores } \\
\text { de serviços" }\end{array}$ \\
\hline $\begin{array}{l}\text { Ostrom } \\
(1996, \text { p. } 1073)\end{array}$ & $\begin{array}{l}\text { "O processo pelo qual os insumos usados para fornecer um bem ou serviço são } \\
\text { contribuídos por indivíduos que não estão na mesma organização" }\end{array}$
\end{tabular}

(CONTINUA) 


\section{(CONTINUAÇÃO)}

Boyle e Harris (2009, p. “Coprodução significa prestar serviços públicos em um relacionamento igual e 11) recíproco entre profissionais, pessoas que usam serviços, suas famílias e seus vizinhos"

Bovaird e Loeffler "Coprodução significa serviços públicos e cidadãos fazendo melhor uso dos (2016, p. 1006) $\quad$ recursos uns dos outros para alcançar melhores resultados ou melhorar a eficiência"

Fonte: elaboração própria.

Etgar (2008), visando explicar como ocorre a coprodução, propôs etapas de engajamento ao longo do processo de coprodução de serviços, que consiste em cinco estágios, que podem ser observados no Quadro 2. Nesse modelo é possível notar os fatores que influenciam a propensão do cidadão a coproduzir, desde o desenvolvimento de condições antecedentes até a geração e avaliação dos resultados do processo.

Quadro 2 - Estágios do processo de coprodução

\begin{tabular}{|l|l|}
\hline Estágio & Descrição \\
\hline & $\begin{array}{l}\text { (1.1) Condições macro ambientais (aspectos econômicos, culturais e tecnológicos, } \\
\text { comunicação e cultura de consumo) } \\
\text { (1.2) Fatores ligados ao usuário (características pessoais, o tempo disponível, o } \\
\text { perfil, as competências e capacidades dos indivíduos) } \\
\text { (1) Desenvolvimento de Fatores ligados ao produto/serviço (possibilidade de customização, atributos } \\
\text { condições antecedentes } \\
\text { do produto/serviço, percepção dos consumidores sobre a necessidade de } \\
\text { customização do produto/serviço) } \\
\text { (1.4) Fatores situacionais (interação de indivíduos coprodutores entre si e } \\
\text { interação com o provedor de serviços, comunicação das organizações com os } \\
\text { usuários e mecanismos promovidos para incentivar a coprodução) }\end{array}$ \\
\hline $\begin{array}{l}\text { (2) Desenvolvimento de indivíduos, } \\
\text { motivações }\end{array}$ & $\begin{array}{l}\text { Fatores econômicos, psicológicos e sociais impulsionariam os iam } \\
\text { motivando-os a participar em atividades de coprodução. }\end{array}$ \\
\hline $\begin{array}{l}\text { (3) Cálculo do custo- } \\
\text { benefício da coprodução }\end{array}$ & $\begin{array}{l}\text { Decisão consciente de envolver-se ou não em atividades de coprodução a partir da } \\
\text { análise dos benefícios e custos esperados. }\end{array}$ \\
\hline (4) Ativação & $\begin{array}{l}\text { Consumidores escolhem os níveis da cadeia de atividades de produção-consumo } \\
\text { em que desejam participar. }\end{array}$ \\
\hline $\begin{array}{l}\text { (5) Geração e avaliação de } \\
\text { resultados do processo }\end{array}$ & $\begin{array}{l}\text { Comparação entre os benefícios obtidos por meio do processo de coprodução e os } \\
\text { benefícios esperados. }\end{array}$ \\
\hline
\end{tabular}

Fonte: adaptado de Etgar (2008).

Como se observa no modelo proposto por Etgar (2008), no estágio de ativação o usuário escolhe os níveis da cadeia de atividades nos quais deseja se engajar, no ciclo do serviço. Para tanto, é necessário que o usuário conheça as formas pelas quais pode participar no processo de produção de serviços (SUNSTEIN; THALER, 2008). Assim, as atividades de coprodução sob responsabilidade do usuário estariam mais especificamente ligadas às etapas de gerenciamento e entrega de serviços (LUSCH; VARGO, 2006).

Entretanto, diversos autores tratam das atividades de coprodução como sendo parte de várias fases do ciclo de serviço (BOVAIRD, 2007; ETGAR, 2008; LOEFFLER et al., 2008; NABATCHI; SANCINO; SICILIA, 2017, PESTOFF, 2006). Bovaird (2007) destaca a relevância da coprodução não somente na fase de entrega, mas também podendo "se estender 
por toda a cadeia de valor de planejamento de serviços, design, comissionamento, gerenciamento, entrega, monitoramento e atividades de avaliação" (BOVAIRD, 2007, p. 847). Assim, o Quadro 3 exemplifica atividades de coprodução que ocorrem ao longo do ciclo de serviços.

Quadro 3 - Coprodução nas fases do ciclo de serviço

\begin{tabular}{|c|c|c|c|}
\hline $\begin{array}{c}\text { Fase do Ciclo de } \\
\text { Serviço }\end{array}$ & Conceito & $\begin{array}{l}\text { Natureza } \\
\text { Temporal } \\
\end{array}$ & Exemplos \\
\hline \multirow{2}{*}{$\begin{array}{l}\text { Co- } \\
\text { commissioning }\end{array}$} & \multirow{2}{*}{$\begin{array}{l}\text { “o que precisa ser } \\
\text { entregue, para quem e } \\
\text { para alcançar quais } \\
\text { resultados” } \\
\text { (BOVAIRD; } \\
\text { LOEFFLER, 2012, p. } \\
\text { 6) }\end{array}$} & \multirow{2}{*}{$\begin{array}{l}\text { Prospectiva } \\
\text { (orientada para o } \\
\text { futuro) }\end{array}$} & $\begin{array}{l}\text { Funcionários públicos e cidadãos trabalham } \\
\text { juntos para definir prioridades } \\
\text { orçamentárias para uma comunidade } \\
\text { (BOVAIRD, 2007; BARBERA; SICILIA; } \\
\text { STECCOLINI, 2016) }\end{array}$ \\
\hline & & & $\begin{array}{l}\text { Departamentos de polícia trabalham com } \\
\text { moradores para identificar prioridade ou } \\
\text { áreas-alvo para esforços de segurança da } \\
\text { comunidade e patrulhas policiais (LAYNE, } \\
\text { 1989). }\end{array}$ \\
\hline Co-designing & $\begin{array}{c}\text { Incorporam a } \\
\text { experiência dos } \\
\text { usuários na criação, } \\
\text { planejamento ou } \\
\text { arranjos de serviços } \\
\text { públicos (BOVAIRD; } \\
\text { LOEFFLER 2012, p. 9) }\end{array}$ & $\begin{array}{l}\text { Prospectiva ou } \\
\text { Concomitante } \\
\text { (orientada para o } \\
\text { futuro ou está } \\
\text { ocorrendo) }\end{array}$ & $\begin{array}{l}\text { Atores estatais e leigos trabalham juntos } \\
\text { para redesenhar um site para serviços de } \\
\text { atendimento a adultos (BOVAIRD; } \\
\text { LOEFFLER, 2012). }\end{array}$ \\
\hline \multirow[b]{2}{*}{ Co-delivery } & \multirow{2}{*}{$\begin{array}{c}\text { Atividades conjuntas } \\
\text { utilizadas para fornecer } \\
\text { diretamente serviços ou } \\
\text { para melhorar a } \\
\text { prestação de serviços } \\
\text { (ALFORD; O } \\
\text { 'FLYNN, 2012; } \\
\text { THOMAS, 2013a, } \\
\text { 2013b). }\end{array}$} & \multirow{2}{*}{$\begin{array}{l}\text { Concomitante } \\
\text { (atualmente existe } \\
\text { ou está } \\
\text { ocorrendo) }\end{array}$} & $\begin{array}{l}\text { Os pais trabalham com professores e } \\
\text { escolas para fornecer aulas ou atividades } \\
\text { extracurriculares para } \\
\text { (PESTOFF, 2006). }\end{array}$ \\
\hline & & & $\begin{array}{l}\text { Os estudantes ajudam a universidade a } \\
\text { organizar dia de boas-vindas (BRANDSEN; } \\
\text { HONINGH, 2016). }\end{array}$ \\
\hline Co-assessment & $\begin{array}{c}\text { monitoramento e } \\
\text { avaliação de serviços } \\
\text { públicos (NABATCHI; } \\
\text { SANCINO; SICILIA, } \\
\text { 2017) }\end{array}$ & $\begin{array}{l}\text { Retrospectiva } \\
\text { (às vezes com } \\
\text { elementos } \\
\text { prospectivos) }\end{array}$ & $\begin{array}{l}\text { Atores estatais e moradores com demência } \\
\text { percorrem bairros para avaliar a facilidade } \\
\text { da navegação (BOVAIRD; LOEFFLER, } \\
\text { 2012). }\end{array}$ \\
\hline
\end{tabular}

Fonte: adaptado de Nabatchi, Sancino e Sicilia (2017).

Além das atividades pelas quais os cidadãos podem contribuir com a prestação de serviços, a coprodução pode apresentar-se de diferentes formas na interação entre o governo e os cidadãos, podendo os indivíduos manifestarem diferentes níveis de envolvimento. Nesse sentido, diversos autores (BITNER et al., 1997; BRUDNEY; ENGLAND, 1983; ETGAR, 2008; NABATCHI; SANCINO; SICILIA, 2017; PERCY, 1978; PESTOFF, 2006; SALM; MENEGASSO, 2010; WHITAKER, 1980) trataram sobre tipologias de participação dos indivíduos no processo de interação com provedores de serviços, com o objetivo de compreender mais profundamente sob quais formas este fenômeno pode ocorrer. 
No que diz respeito ao processo de coprodução, Whitaker (1980) sugeriu três tipos de atividades em que o cidadão contribuiria para a produção de serviços públicos, sendo elas: (1) a solicitação de assistência ao agente público, (2) o fornecimento de assistência ao agente público pelo indivíduo e (3) a interação entre o agente e o cidadão, com o intuito de ajustar as ações e expectativas de ambos. Assim sendo, vários serviços públicos são prestados em resposta a pedidos específicos dos cidadãos. É o caso, por exemplo, de organizações governamentais que prestam serviços de emergência, tais como: polícias, bombeiros, serviços de atendimento de saúde, entre outros.

Outra importante forma de coprodução estaria ligada ao fornecimento de assistência ao agente público pelos cidadãos, sendo esta considerada essencial para o sucesso de muitas políticas públicas (WHITAKER, 1980). É o caso, por exemplo, de serviços de coleta seletiva de lixo e reciclagem, em que o empenho individual e coletivo dos cidadãos é imprescindível para que a política como um todo possa atingir seus objetivos e levar a um benefício social. Outro exemplo pode ser apreciado no âmbito dos serviços de segurança pública, em que os cidadãos poderiam cooperar ao ficar atentos ao que ocorre em suas vizinhanças instalando alarmes, monitorando câmeras de segurança, entre outras medidas que visassem contribuir para um ambiente mais seguro (ROSENTRAUB; SHARP, 1981).

Whitaker (1980) evidenciou uma terceira possibilidade de coprodução na prestação de serviços, que envolveria um ajustamento mútuo entre cidadãos e agentes públicos em que ocorre mais do que a solicitação de assistência por parte dos indivíduos, uma vez que a interação entre os atores é essencial pois os cidadãos e agentes públicos devem definir seus papéis para a solução de uma demanda social complexa. Este seria o caso de serviços que possuem como objetivo uma mudança no comportamento dos usuários, como por exemplo serviços de saúde. Nesse tipo de serviço, paciente e médico, ainda que possuam diferentes papéis durante o processo de prestação do serviço, devem interagir de forma recíproca. Nesse caso, espera-se que o paciente colabore durante e após o atendimento, de modo a seguir as recomendações sugeridas pelo médico para que o serviço possa solucionar a demanda inicial, cumprindo o objetivo de ambos os atores envolvidos.

Além das formas sugeridas por Whitaker (1980), Brudney e England (1983) propuseram como tipologia o nível de interação entre os indivíduos, podendo apresentar-se como individual, em grupos ou coletiva. No nível individual, o cidadão poderia atuar de forma que o benefício social das atividades de coprodução seria recebido pelo próprio usuário coprodutor. No nível de grupos, a coprodução envolve a participação de alguns indivíduos e 
pode requerer mecanismos formais de coordenação entre grupos de cidadãos e agentes públicos (BRUDNEY; ENGLAND, 1983), com a possibilidade de que os benefícios sejam individualmente ou grupalmente experimentados (BOVAIRD et al., 2015). Já a coprodução coletiva contribui com insumos para gerar benefícios que possam abranger todos os possíveis usuários do serviço, não sendo limitada a um grupo seleto de coprodutores. Percy (1978) enfatiza que o nível de interação entre os cidadãos, sua coesão e organização em vizinhanças, bem como as redes de colaboração existentes, podem influenciar a coprodução coletiva.

A partir de um estudo no âmbito da educação infantil europeia, Pestoff (2006) aprofundou a investigação de formas de participação do cidadão na prestação de serviços educacionais, identificando as dimensões econômica, política, pedagógica e social. Essas formas de coprodução estão ligadas ao tipo de esforço desempenhado e à forma com que o cidadão opta por contribuir com a prestação do serviço. A dimensão econômica consiste em auxílio financeiro à execução de melhorias na entrega de serviços, tais como doações em dinheiro, enquanto a dimensão política relaciona-se ao envolvimento do cidadão na tomada de decisões que influenciam a prestação do serviço, tais como Conselhos Comunitários. A dimensão pedagógica está ligada à interação e suporte ao aprendizado dos alunos no caso de escolas, enquanto a dimensão social consiste na participação e engajamento de familiares em eventos escolares (PESTOFF, 2006). A partir dessas diferentes formas e dimensões propostas, o Quadro 4 apresenta uma compilação das principais formas de coprodução na literatura.

Quadro 4 - Formas de coprodução

\begin{tabular}{|c|c|c|}
\hline Referência & Tipologias & Níveis de coprodução \\
\hline Percy (1978) & $\begin{array}{l}\text { Por níveis de cooperação com } \\
\text { cidadãos } \\
\text { Por níveis de cooperação com } \\
\text { agentes públicos }\end{array}$ & $\begin{array}{l}\text { Individuais/Grupais/Coletivas } \\
\text { Pouca ou nenhuma cooperação com o } \\
\text { agente público } \\
\text { Cooperação direta com o agente } \\
\text { público }\end{array}$ \\
\hline \multirow{3}{*}{ Whitaker (1980) } & \multirow{3}{*}{$\begin{array}{l}\text { Atividades desempenhadas pelo } \\
\text { cidadão }\end{array}$} & $\begin{array}{l}\text { Solicitação de assistência ao agente } \\
\text { público }\end{array}$ \\
\hline & & $\begin{array}{l}\text { Fornecimento de assistência ao agente } \\
\text { público pelo indivíduo }\end{array}$ \\
\hline & & $\begin{array}{l}\text { Interação entre o cidadão e o agente } \\
\text { público }\end{array}$ \\
\hline \multirow{3}{*}{ Brudney e England (1983) } & \multirow{3}{*}{ Por níveis de interação } & Individual \\
\hline & & Em grupos \\
\hline & & Coletiva \\
\hline \multirow{4}{*}{ Pestoff (2006) } & \multirow{4}{*}{$\begin{array}{l}\text { Dimensões de participação do } \\
\text { cidadão na prestação de serviços }\end{array}$} & Econômica \\
\hline & & Política \\
\hline & & Pedagógica \\
\hline & & Social \\
\hline
\end{tabular}

Fonte: elaboração própria. 
A partir da identificação de tipologias de coprodução e as formas pelas quais os cidadãos podem contribuir com a prestação de serviços, torna-se relevante compreender como se desenvolve a coprodução no âmbito da segurança pública.

\subsection{Coprodução da segurança}

Segundo Percy (1978), os cidadãos não são apenas clientes dos serviços de polícia, mas possuem papel ativo na produção e consumo de segurança, podendo atuar como coprodutores. Algumas ações seriam, por exemplo, "manter-se alerta e reportar situações suspeitas nas vizinhanças, cooperar com a investigação de crimes e empenhar esforços para impedir o vandalismo" (RICH, 1981, p. 61). Osborne e Gaebler (1992) relatam uma mudança que se iniciou na década de 1980 nos Estados Unidos quanto ao redirecionamento das atividades policiais para um "policiamento orientado para a comunidade", que seria um método em que os órgãos de segurança pública não apenas reagem a situações criminosas, mas também atuam de forma a se aproximar da sociedade, ajudando a comunidade a resolver problemas advindos de atividades criminosas (OSBORNE; GAEBLER, 1992). Algumas das ações que passaram a ser implementadas pelas polícias norte americanas envolvem a instrução de policiais para criar vínculos com diversos atores sociais com o intuito de se aproximar da comunidade, como por exemplo, visitar as famílias, conversar com os cidadãos acerca dos problemas de segurança locais e criação de grupos de vigilância de bairro (WILLIAMS et al., 2016).

Assim, o envolvimento dos cidadãos em ações relativas à segurança por meio de atividades de coprodução passou a ser considerado essencial para a promoção da segurança pública. Percy (1978) apresenta uma matriz, considerando como dimensões de atividades de coprodução o nível de cooperação entre os cidadãos e o nível de cooperação com instituições de polícia/segurança, considerando (1) atividades individuais do cidadão; (2) atividades grupais ou conjuntas; (3) atividades desenvolvidas pelos cidadãos em cooperação direta com a polícia, (4) atividades desenvolvidas sem ou com pouca cooperação com a polícia. O Quadro 5 apresenta exemplos de atividades de coprodução de segurança desenvolvidas pelos cidadãos a partir das dimensões apresentadas por Percy (1978, p. 488). 
Quadro 5 - Dimensões de atividades de coprodução de segurança desenvolvidas pelo cidadão

\begin{tabular}{|c|l|l|}
\hline & \multicolumn{2}{|c|}{ Nível de cooperação com cidadãos } \\
\hline $\begin{array}{c}\text { Cooperação } \\
\text { com a polícia }\end{array}$ & \multicolumn{1}{|c|}{ Atividade individual/doméstica } & \multicolumn{1}{c|}{ Atividade grupal } \\
\hline $\begin{array}{c}\text { Pouca ou } \\
\text { nenhuma } \\
\text { cooperação } \\
\text { com a polícia }\end{array}$ & $\begin{array}{l}\text { Adicionar fechaduras de segurança em casa. } \\
\text { Evitar regiões perigosas da cidade. } \\
\text { Instalar dispositivos de iluminação e alarme. } \\
\text { Aprender habilidades de autoproteção. }\end{array}$ & $\begin{array}{l}\text { Patrulha móvel cidadã (organizada de forma } \\
\text { independente). } \\
\text { Formação de grupos com foco em prevenção } \\
\text { de crimes dividades na vizinhança. } \\
\text { Uso de grupos para informar outros } \\
\text { motoristas sobre problemas no tráfego ou } \\
\text { acidentes de trânsito. }\end{array}$ \\
$\begin{array}{c}\text { Cooperação } \\
\text { direta com a } \\
\text { polícia }\end{array}$ & $\begin{array}{l}\text { Cidadãos servindo como voluntários } \\
\text { (auxiliares) policiais. } \\
\text { Cidadãos fazendo patrulhas com policiais. } \\
\text { Oferecer informação para a polícia. } \\
\text { Reportar circunstâncias suspeitas à polícia. }\end{array}$ & $\begin{array}{l}\text { Grupos que distribuem informações sobre } \\
\text { prevenção de crimes com assistência da } \\
\text { polícia. } \\
\text { Grupos de interação comunidade-polícia } \\
\text { Conselhos comunidade-polícia } \\
\text { auxiliam na formulação de políticas } \\
\text { públicas) }\end{array}$ \\
\hline
\end{tabular}

Fonte: adaptado de Percy (1978).

Para Schneider (1987) a coprodução de segurança no nível individual depende da demanda individual por segurança; de recursos que o indivíduo possua para aumentar a segurança pessoal; e do conhecimento sobre as formas pelas quais pode aumentar seu nível de segurança. No nível coletivo, a coprodução ocorre, por exemplo, por meio da formação de grupos para assistência a vítimas de crimes e proteção da vizinhança, como pessoas que ajudam a cuidar das propriedades, que solicitam ajuda aos vizinhos e relatam comportamentos suspeitos.

Por meio da realização de grupos focais em países europeus, Loeffler et al. (2008) identificaram e investigaram quantitativamente sete indicadores de coprodução de segurança, que envolvem 1) Tomar o cuidado de fechar portas e janelas da residência; 2) Vigiar a residência de vizinhos; 3) Solicitar que os vizinhos vigiem a residência; 4) Reportar crimes à polícia; 5) Reportar problemas de segurança da comunidade; 6) Participar em grupos de segurança pública; 7) Solicitar informações/dicas sobre segurança à polícia. Como é possível observar por meio desses indicadores, tratando-se de bens públicos e da prestação de serviços por parte do governo para provê-los, observa-se que o papel do cidadão não envolve apenas a sua contribuição direta com órgãos do governo.

Para Rosentraub e Sharp (1981) ações individuais realizadas pelos cidadãos também influenciam a utilização de recursos por parte do governo e a prestação de serviços públicos. 
No caso da segurança, o investimento individual do cidadão em dispositivos para sua proteção pode influenciar o nível de recursos que a polícia e os órgãos de segurança pública dedicam para promover a proteção dos cidadãos (ROSENTRAUB; SHARP, 1981). Schneider (1987, p. 612) destaca que "a coprodução pode ocorrer quando existe uma política ou programa público com o qual cidadãos podem agir em conjunto ou ao longo de trilhas paralelas e os resultados das ações podem produzir benefícios individuais, grupais ou coletivos”.

Nesse sentido, as ações individuais e as coletivas de coprodução desempenhadas pelos cidadãos, ainda que sem cooperação direta com os órgãos de segurança pública, podem gerar o que Nabatchi, Sancino e Sicilia (2017) chamam de spillover effects, ou efeitos de transbordamento. Esses efeitos podem gerar benefícios sociais, ainda que a contribuição do cidadão tenha sido realizada visando a obtenção de benefícios pessoais, ou seja, podem gerar externalidades positivas (NABATCHI; SANCINO; SICILIA, 2017, p. 769). Alford e Yates (2015) destacam que a maioria das atividades de coprodução desempenhadas pelos cidadãos é realizada para produzir valor privado e de forma que haja pouco contato com outras pessoas para realizar determinada ação. Ademais, os cidadãos possuem maior propensão a se envolverem em atividades em que haja reciprocidade, como por exemplo, os vizinhos vigiarem as casas uns dos outros (ALFORD; YATES, 2015).

É o caso da instalação de câmeras de segurança voltadas para a rua na residência de determinado cidadão que as tenha instalado com o intuito de autoproteção, mas que podem inibir a ação de criminosos ou servir posteriormente para a identificação de indivíduos que tenham cometido crimes na vizinhança. Ainda que o intuito do cidadão tenha sido o benefício pessoal, a ação realizada pode gerar efeitos para um grupo, como os moradores da rua, ou para o fortalecimento da segurança da região. A partir da evolução nos estudos sobre coprodução e a proposição de tipologias e modelos para explicar a ocorrência do fenômeno, a literatura foi se desenvolvendo ao longo do tempo. Assim, ao se compreender as formas pelas quais as atividades de coprodução desempenhadas pelo cidadão podem ocorrer, torna-se possível identificar iniciativas de estímulo que tornariam o cidadão mais propenso a contribuir. 


\section{METODOLOGIA}

Este estudo caracteriza-se como uma pesquisa exploratória e descritiva, visto que busca identificar como ocorre o fenômeno da coprodução, suas formas a partir das atividades de coprodução apresentadas pelos cidadãos e a propensão do cidadão à coprodução de segurança. Considerando que a literatura sobre coprodução é majoritariamente internacional e que a conjuntura brasileira, especialmente no que diz respeito às questões de segurança pública difere consideravelmente de outros países, fez-se necessária a exploração das atividades e formas de coprodução a partir da realidade nacional, e mais especificamente, distrital. Este tipo de pesquisa mostrou-se o mais indicado devido à necessidade de se explorar o objeto de pesquisa levando em consideração a realidade em que ele se insere (CRESWELL, 2010) e o intuito de descrever de que modo o fenômeno ocorre para melhor entendê-lo (GIL, 2002) a partir de seus significados e singularidades (MINAYO, 2017).

A Lei Orgânica do Distrito Federal prevê em seu artigo $3^{\circ}$ inciso VI como um dos objetivos do Distrito Federal o atendimento das demandas da sociedade nas áreas relativas à prestação dos serviços de segurança como prioridade, dentre outros serviços públicos essenciais (DISTRITO FEDERAL, 1993). Nesse sentido, o governo e os cidadãos são conjuntamente responsáveis para que haja uma prestação dos serviços públicos de segurança mais eficientes, especialmente devido à ênfase na prevenção à criminalidade e desordens evidenciada nos dispositivos legais. Como estratégia para uma orientação mais eficiente das ações dos órgãos de segurança, o governo do Distrito Federal criou uma divisão das regiões administrativas em quatro regiões maiores, denominadas Regiões Integradas de Segurança Pública (RISP), sendo elas: Metropolitana, Oeste, Sul e Leste (DISTRITO FEDERAL, 2018).

Com relação à abordagem, o presente estudo caracteriza-se como uma pesquisa qualitativa. Com o intuito de assegurar a representatividade dos dados, garantiu-se que fossem entrevistados membros e participantes atuantes em mecanismos (Conselhos Comunitários de Segurança das regiões administrativas do DF) de coprodução e cidadãos de todas as RISP, considerando a variedade das regiões com relação ao perfil sociodemográfico dos residentes e às diferentes características das RISP. Foram entrevistados 82 cidadãos residentes no Distrito Federal, sendo 22 cidadãos engajados em mecanismos de coprodução e 60 cidadãos não engajados em mecanismos formais.

Para a seleção dos cidadãos utilizou-se de amostragem não probabilística, por meio da técnica snowball que é uma amostragem que utiliza cadeias de referência que se iniciam por 
meio de sujeitos-chave, que indicam pessoas com o perfil para participação na pesquisa (VINUTO, 2016). O instrumento de coleta de dados foi um roteiro semiestruturado composto por duas perguntas abertas. Para a análise dos dados, utilizou-se a análise de conteúdo (BARDIN, 2016), sendo que as categorias foram identificadas utilizando-se a técnica de saturação teórica, que "designa o momento em que o acréscimo de dados e informações em uma pesquisa não altera a compreensão do fenômeno estudado" (THIRY-CHERQUES, 2009, p. 21). Assim, tornou-se possível verificar a cada entrevista os enunciados confirmados e incluídos até que não houvesse mais novos enunciados nas declarações dos entrevistados (FALQUETO; FARIAS, 2012).

No Quadro 6 é possível visualizar um resumo da metodologia utilizada na pesquisa, apresentando os objetivos da pesquisa, as perguntas dirigidas aos respondentes, a fonte dos dados e as técnicas de análise de dados.

Quadro 6 - Resumo da metodologia

\begin{tabular}{|c|c|c|c|}
\hline Objetivos & Perguntas abertas & Fonte dos dados & $\begin{array}{c}\text { Técnica de } \\
\text { análise }\end{array}$ \\
\hline $\begin{array}{l}\text { Identificar as atividades e } \\
\text { formas de coprodução de } \\
\text { segurança desenvolvidas } \\
\text { pelos cidadãos }\end{array}$ & $\begin{array}{l}\text { Quais atividades você e outros } \\
\text { moradores da região desenvolvem } \\
\text { para colaborar com a sua } \\
\begin{array}{l}\text { segurança e a de } \\
\text { vizinhanças? }\end{array}\end{array}$ & $\begin{array}{l}\text { Cidadãos engajados e não } \\
\text { engajados em mecanismos } \\
\text { de coprodução residentes no } \\
\text { Distrito Federal }\end{array}$ & \multirow{2}{*}{$\begin{array}{l}\text { Análise de } \\
\text { Conteúdo } \\
\text { (Saturação } \\
\text { Teórica) }\end{array}$} \\
\hline $\begin{array}{l}\text { Verificar a propensão do } \\
\text { cidadão para coproduzir } \\
\text { segurança }\end{array}$ & $\begin{array}{l}\text { O que o tornaria mais disposto a } \\
\text { colaborar com a segurança da } \\
\text { região onde mora? }\end{array}$ & $\begin{array}{l}\text { Cidadãos não engajados em } \\
\text { mecanismos de coprodução } \\
\text { residentes no Distrito } \\
\text { Federal }\end{array}$ & \\
\hline
\end{tabular}

Fonte: elaboração própria.

\section{ANÁLISE E DISCUSSÃO DOS RESULTADOS}

Nessa seção serão discutem-se os resultados da pesquisa, iniciando-se pela descrição e discussão das atividades e formas de coprodução de segurança desenvolvidas pelos cidadãos. Logo após, apresentam-se os resultados sobre a propensão do cidadão para coproduzir segurança. 


\subsection{Atividades e Formas de coprodução}

Para descrever as atividades de coprodução apresentadas pelos cidadãos da pesquisa, perguntaram-se aos cidadãos engajados em mecanismos de coprodução e aos cidadãos residentes nas regiões administrativas, quais atividades eles e outros moradores desenvolvem para sua própria segurança e para colaborar com a segurança de sua vizinhança. A partir das entrevistas, foi possível identificar as principais ações constantes dos conteúdos das declarações dos cidadãos para contribuir com a segurança nos níveis individual, grupal e coletivo. No Quadro 7, que apresenta as principais atividades de coprodução a partir dos níveis de cooperação entre os cidadãos e o nível de interação com órgãos de segurança pública, é possível verificar a frequência com que as atividades foram citadas nas declarações dos cidadãos, dentre os 82 entrevistados no estudo.

Quadro 7 - Principais atividades de coprodução desempenhadas pelos cidadãos

\begin{tabular}{|c|c|c|}
\hline \multirow{2}{*}{$\begin{array}{l}\text { Interação com } \\
\text { órgãos }\end{array}$} & \multicolumn{2}{|c|}{ Nível de cooperação com cidadãos } \\
\hline & Atividade individual & Atividade grupal/coletiva \\
\hline $\begin{array}{c}\text { Pouca ou } \\
\text { nenhuma } \\
\text { interação com } \\
\text { órgãos de } \\
\text { segurança }\end{array}$ & $\begin{array}{l}\text { Vigiar as atividades na vizinhança } \\
(\mathrm{f}=42 / 82) \text {; } \\
\text { Instalar câmeras de monitoramento na } \\
\text { própria residência ( } \mathrm{f}=27 / 82) ; \\
\text { Conscientizar vizinhos e outros } \\
\text { moradores sobre questões relativas à } \\
\text { segurança ( } \mathrm{f}=19 / 82) \text {; } \\
\text { Transitar pela cidade atento à } \\
\text { movimentação de pessoas ao redor (f = } \\
11 / 82) ; \\
\text { Instalar dispositivos de iluminação, } \\
\text { alarme e cercas }(\mathrm{f}=10 / 82) ; \\
\text { Manter as portas de casa trancadas em } \\
\text { todos os momentos }(\mathrm{f}=6 / 82) \text {. }\end{array}$ & $\begin{array}{l}\text { Pedir para que vizinhos vigiem atividades na } \\
\text { vizinhança (f =42/82); } \\
\text { Compartilhamento de informações via grupos } \\
\text { de WhatsApp (grupos de moradores sem } \\
\text { participação de órgãos) (f =36/82); } \\
\text { Formação de grupos com foco em prevenção } \\
\text { de crimes e causas relativas à segurança } \\
\text { pública (f =13/82); } \\
\text { Contratação de vigia e implantação de guarita } \\
\text { pelos moradores em determinadas localidades } \\
(\mathrm{f}=11 / 82) \text {; } \\
\text { Instalar câmeras de monitoramento na } \\
\text { vizinhança em colaboração com outros } \\
\text { moradores }(\mathrm{f}=9 / 82) \text {. }\end{array}$ \\
\hline $\begin{array}{l}\text { Interação direta } \\
\text { com órgãos de } \\
\text { segurança }\end{array}$ & $\begin{array}{l}\text { Oferecer informações, sugestões, } \\
\text { críticas e demandas aos órgãos de } \\
\text { segurança pública } \\
\text { (f=22/82); } \\
\text { Denunciar circunstâncias suspeitas aos } \\
\text { órgãos de segurança }(\mathrm{f}=19 / 82) \text {; } \\
\text { Cidadão solicitar serviços de órgãos de } \\
\text { segurança pública }(\mathrm{f}=11 / 82) \text {; } \\
\text { Cidadão disponibilizar acesso às } \\
\text { imagens de vídeo de sua vizinhança aos } \\
\text { órgãos de segurança por meio de } \\
\text { aplicativos de celular e sítios da internet } \\
\text { (f =5/82); } \\
\text { Cidadão observar câmeras públicas que } \\
\text { disponibilizam imagens de vídeo da } \\
\text { vizinhança } 24 h \text { por meio de aplicativos } \\
\text { de celular e sítios da internet (f =4/82). }\end{array}$ & $\begin{array}{l}\text { Oferecer informações, sugestões, críticas e } \\
\text { demandas aos Conselhos Comunitários de } \\
\text { Segurança (f=18/82); } \\
\text { Cidadão servindo como voluntário (auxiliar) } \\
\text { atuando como membro dos conselhos } \\
\text { comunitários de segurança (f }=18 / 82) \text {; } \\
\text { Compartilhamento de informações via grupos } \\
\text { de WhatsApp (grupos de moradores com } \\
\text { membros de órgãos de segurança pública } \\
\text { incluídos) (f =13/82); } \\
\text { Participação em grupos que distribuem } \\
\text { informações sobre prevenção de crimes com } \\
\text { assistência da polícia (f }=9 / 82) \text {; } \\
\text { Alimentação do mapeamento de desordens } \\
\text { públicas (f=2/82). }\end{array}$ \\
\hline
\end{tabular}

Fonte: elaboração própria. 
A partir da identificação das atividades em que ocorre interação do cidadão com os órgãos de segurança pública, tornou-se possível elencar os exemplos de coprodução observados na prestação de serviços públicos de segurança a partir das categorias a priori delineadas por Nabatchi, Sancino e Sicilia (2017) - co-comissioning, co-designing, codelivery e co-assessment - como pode ser visto no Quadro 8.

Quadro 8 - Exemplos de coprodução da segurança observados nas declarações de cidadãos engajados e não engajados em mecanismos de coprodução

\begin{tabular}{|c|c|c|}
\hline Categorias a priori & Exemplos observados & $\begin{array}{c}\text { Entrevistas: conteúdo verificado nas } \\
\text { declarações }\end{array}$ \\
\hline $\begin{array}{l}\text { Co-commissioning } \\
\text { (Nabatchi; Sancino; } \\
\text { Sicilia, 2017) }\end{array}$ & $\begin{array}{l}\text { Interação entre órgãos de segurança e } \\
\text { cidadãos para definir a solução de } \\
\text { demandas prioritárias de segurança na } \\
\text { região }\end{array}$ & $\begin{array}{l}\text { Reuniões dos Conselhos Comunitários } \\
\text { de Segurança; Participação em grupos } \\
\text { de interação comunidade-polícia. }\end{array}$ \\
\hline $\begin{array}{l}\text { Co-designing } \\
\text { (Nabatchi; Sancino; } \\
\text { Sicilia, 2017) }\end{array}$ & $\begin{array}{l}\text { Órgãos de segurança e cidadãos } \\
\text { engajados atuam em conjunto para } \\
\text { desenvolver aplicativos que contribuam } \\
\text { para a segurança pública }\end{array}$ & $\begin{array}{l}\text { Criação e alimentação do mapeamento } \\
\text { de desordens públicas }\end{array}$ \\
\hline \multirow{3}{*}{$\begin{array}{c}\text { Co-delivery } \\
\text { (Nabatchi; Sancino; } \\
\text { Sicilia, 2017) }\end{array}$} & $\begin{array}{l}\text { Cidadãos se organizam para } \\
\text { conscientizar outros moradores com o } \\
\text { objetivo de melhorar a segurança na } \\
\text { região }\end{array}$ & $\begin{array}{l}\text { Grupos de conversa sobre segurança } \\
\text { pública para conscientizar os moradores } \\
\text { da vizinhança; Síndicos de prédios } \\
\text { oferecem cursos a porteiros e vigias; } \\
\text { Conselhos Comunitários promovem } \\
\text { cursos sobre segurança pública aos } \\
\text { cidadãos. }\end{array}$ \\
\hline & $\begin{array}{l}\text { Fornecimento de assistência ao órgão } \\
\text { de segurança pelo cidadão }\end{array}$ & $\begin{array}{l}\text { Cidadão disponibilizar acesso às } \\
\text { imagens de vídeo de sua vizinhança aos } \\
\text { órgãos de segurança por meio de } \\
\text { aplicativos de celular e sítios da internet; } \\
\text { Cidadão denunciar situações suspeitas e } \\
\text { crimes à polícia; Compartilhamento de } \\
\text { informações via grupos de WhatsApp } \\
\text { que incluem moradores e membros de } \\
\text { órgãos de segurança pública. }\end{array}$ \\
\hline & $\begin{array}{l}\text { Solicitação de assistência aos órgãos de } \\
\text { segurança pública pelo cidadão }\end{array}$ & $\begin{array}{l}\text { Cidadão solicitar atendimento aos } \\
\text { órgãos de segurança pública }\end{array}$ \\
\hline $\begin{array}{c}\text { Co-assessment } \\
\text { (Nabatchi; Sancino; } \\
\text { Sicilia, 2017) }\end{array}$ & $\begin{array}{l}\text { Cidadãos oferecem informações, } \\
\text { sugestões e críticas sobre segurança ao } \\
\text { governo }\end{array}$ & $\begin{array}{l}\text { Oferecer informações aos órgãos de } \\
\text { segurança pública por meio de } \\
\text { ouvidorias e sites governamentais }\end{array}$ \\
\hline
\end{tabular}

Fonte: elaboração própria.

Bovaird (2007) destaca que o envolvimento do cidadão em atividades de coprodução pode ocorrer em diversas etapas da cadeia de prestação de serviço, podendo os cidadãos escolherem aquelas em que desejam se envolver (ETGAR, 2008). Na etapa de cocomissioning, em que ocorre o delineamento dos serviços a serem entregues à população a partir dos resultados almejados (BOVAIRD; LOEFFLER, 2012), foram identificados 
exemplos de coprodução viabilizada pela interação entre cidadãos e órgãos governamentais para definir a solução de demandas e prioridades relacionadas à segurança pública. $\mathrm{O}$ entrevistado 10 destacou a reunião dos Conselhos Comunitários de Segurança como um mecanismo de interação e de coprodução na fase de delineamento da prestação de serviços de segurança, em que os órgãos governamentais interagem com a população para definir as demandas a serem priorizadas, como pode se observar a seguir:

Eu acho que o direito à voz é o maior instrumento que o Conselho Comunitário de Segurança oferece hoje. É a oportunidade de você estar cara a cara com o gestor, é a oportunidade de você falar com o gestor aquilo que você precisa, aquilo que está faltando para que melhore a sua rua. Então o Conselho Comunitário de Segurança visa o coletivo e não o individual, então quando você vai falar com os moradores tem que pensar na sua comunidade, ao que está ao redor da sua casa também (Entrevistado $10)$.

Outro meio citado pelos entrevistados foi a participação em grupos de interação comunidade-polícia, permitindo maior proximidade com os órgãos de segurança de forma rápida e eficiente, tal como enfatiza o entrevistado 6 :

Nós temos esses grupos e nos comunicamos através do WhatsApp. A gente entende como segurança uma calçada que está levantando um pedaço, um parque que está com os brinquedos enferrujados e que merece uma atenção. Por exemplo, uma invasão de área do comércio que pode elevar e um cadeirante não passar. Então isso tudo a gente trabalha com essa comunicação via principalmente celular. Então a tecnologia nos ajuda hoje a encontrar do outro lado uma pessoa que acate essa sua ligação e dentro de pouco tempo vá lá no local e verifique o que está havendo (Entrevistado 6).

$\mathrm{Na}$ etapa de co-designing, em que as experiências dos cidadãos são incorporadas na criação, planejamento ou arranjo de serviços públicos (BOVAIRD; LOEFFLER, 2012; NABATCHI; SANCINO; SICILIA, 2017), os entrevistados 4 e 7 destacaram a atuação conjunta dos cidadãos engajados em mecanismos formais e do governo para o desenvolvimento de aplicativos de celular que possibilitem o mapeamento de desordens públicas e situações que ameacem a segurança pública.

Eu conheci uma que eu acho muito interessante que é o mapeamento das desordens. Isso sim, não deixa de ser através do Conselho Comunitário de Segurança. Embora seja da segurança pública, estamos canalizando tentando buscar preencher essas desordens através das demandas vindas do Conselho Comunitário de Segurança, mas lá na região especificamente nós já estamos buscando envolver os síndicos nessa situação. Os síndicos passarem para um membro que é do Conselho Comunitário de Segurança, que por coincidência é o moderador do grupo da região para mapear essas desordens, essa é uma forma. Ainda não chegou para a população de uma forma geral, somente via representação por meio do Conselho Comunitário de Segurança. Faz muita diferença, se eu passar a ser uma pessoa que esteja atenta a esses mapas de desordem se eu passar a ajudar o governo com o meu olhar e não fechar 
os olhos (Entrevistado 7).

$\mathrm{Na}$ fase de co-delivery, em que ocorre a atuação conjunta entre atores estatais e cidadãos para a entrega direta ou a melhoria de serviços públicos (NABATCHI; SANCINO; SICILIA, 2017), foram observados exemplos de atividades desempenhadas pelos cidadãos. A primeira consiste na organização dos próprios cidadãos para conscientizar os moradores com o objetivo de melhorar a segurança na região em que residem.

Nós temos aqui, especificamente na região, várias iniciativas de treinamento de porteiros com o batalhão da polícia militar. Fizemos em 2015 isso e perdura até hoje, e que você tem o contato do porteiro com o batalhão da polícia militar (Entrevistado 3)

Existem campanhas internas dentro do meu condomínio para os moradores estarem atentos na entrada e saída do condomínio pela garagem, evitar entrar a pé por exemplo. Eu cuidando bem dessa situação ali no meu condomínio, de certa forma eu acredito que eu estou contribuindo sim para melhorar a segurança e conscientizando ainda mais os moradores de que eles precisam estar atentos a isso. A responsabilidade sobre segurança não é só do governo é nossa também. Essa é a contribuição que eu tenho dado, além de estar participando de cursos (Entrevistado 7).

Além disso, ainda na etapa de co-delivery, observou-se que os cidadãos atuam mediante fornecimento e solicitação de assistência aos órgãos de segurança, conforme tipologia proposta por Whitaker (1980):

A gente também contribui muito com as forças de segurança pública, de maneira a apoiar, informar, temos grupos de WhatsApp informando pessoas suspeitas, chamando a viatura por ali (Entrevistado 1)

É um vigiando o outro, porque todo mundo sai, a gente vive em uma cidade dormitório, sai então fica pouca gente. Viu alguma coisa suspeita, põe no grupo e liga todo mundo para a polícia, se um não ligar o outro ligou. Então a gente montou e graças a Deus com relação a isso foi muito bom, o resultado foi positivo (Entrevistado 8)

Por último, na fase de co-assessment, cujo foco encontra-se no monitoramento e avaliação da prestação do serviço público (NABATCHI; SANCINO; SICILIA, 2017), identificou-se que os cidadãos coproduzem ao utilizar espaços de troca de informações como pode ser observado na declaração a seguir:

A forma que nós temos de ajudar e dar nossa opinião também é usando ouvidoria mesmo e os sites, acho que é essa a forma de participar e dar nossa opinião para melhorar essa questão de segurança (Entrevistado 7)

Por meio da identificação das atividades de coprodução de segurança desempenhadas pelos cidadãos, tornou-se possível verificar quais formas foram citadas. Essas atividades foram categorizadas a priori a partir de três formas de coprodução propostas por Pestoff 
(2006) - econômica, política e social - e, ainda a partir da categoria de coprodução de informação (OSTROM, 1996). Foram identificadas a posteriori duas formas principais de coprodução que englobam as demais. Essas duas categorias foram denominadas como: coprodução preventiva e coprodução repressiva. Dentro destas duas formas, observaram-se tantas ações puramente preventivas ou repressivas, como também outras formas de coprodução categorizadas a priori - tais como as formas econômica, política, social e de informação.

Na primeira entrevista, foram identificadas as formas de coprodução preventiva, bem como as categorias econômica e política (PESTOFF, 2006) e a coprodução de informação (OSTROM, 1996). Segundo o entrevistado 1, a participação preventiva do cidadão pode se dar por meio de ações como manter-se atento aos próprios pertences, trancar veículos e residências, entre outras ações que inibam a possibilidade de que o cidadão seja vítima de crimes. Quanto à coprodução econômica (PESTOFF, 2006), o entrevistado descreveu o investimento na compra de equipamentos, tais como câmeras de segurança na residência e nas vizinhanças.

Concernente à coprodução política (PESTOFF, 2006), o entrevistado 1 citou a participação em reuniões dos Conselhos Comunitários de Segurança das regiões administrativas. Esta forma de coprodução ocorre no nível estratégico do planejamento do serviço público, considerando a interação entre cidadãos e órgãos do governo. Ainda considerando a forma de coprodução preventiva, o entrevistado citou a coprodução de informação por meio de aplicativos que avisam outros moradores sobre perigos relacionados à segurança e grupos de trocas de mensagens para alertar sobre situações suspeitas. O Entrevistado 1 também relatou denúncias e informações fornecidas aos órgãos de segurança para a repressão de crimes, o que caracteriza a coprodução como de informação na forma repressiva.

O relato do entrevistado 2 permitiu a confirmação das formas de coprodução preventiva, econômica, política, bem como a coprodução de informação, tanto preventiva como repressiva; enquanto os entrevistados 3 e 4 relataram, respectivamente, a atuação do cidadão ao intervir em situações de ação criminosa e dar voz de prisão a criminosos atuando momentaneamente com o poder de um membro das forças de segurança, categorizando-se como forma de coprodução repressiva. Com o depoimento do entrevistado 5 inclui-se a categoria de coprodução social (PESTOFF, 2006), citando como exemplo a ocupação dos espaços públicos promovendo eventos e ações sociais com o intuito de prevenir o abandono 
de locais públicos. A saturação teórica foi encontrada na quinta entrevista, sendo analisadas pelo menos mais duas entrevistas para a constatação da saturação (THIRY-CHERQUES, 2009), confirmando-se que não foram mais incluídas novas categorias de formas de coprodução de segurança.

A partir da análise da inclusão e confirmação das categorias de coprodução identificadas, verificou-se que a dimensão coprodução pedagógica (PESTOFF, 2006) não se aplicou às formas de coprodução de segurança. Entretanto, foram observadas as categorias de coprodução: econômica, política e social, bem como a coprodução de informação, que nos estudos de Ostrom (1996) mostrou-se fator essencial para o provimento de serviços públicos. O Quadro 9 apresenta as categorias encontradas e os exemplos de formas de coprodução observados.

Quadro 9 - Formas de coprodução de segurança identificadas na atuação de cidadãos engajados e não engajados em mecanismos de coprodução

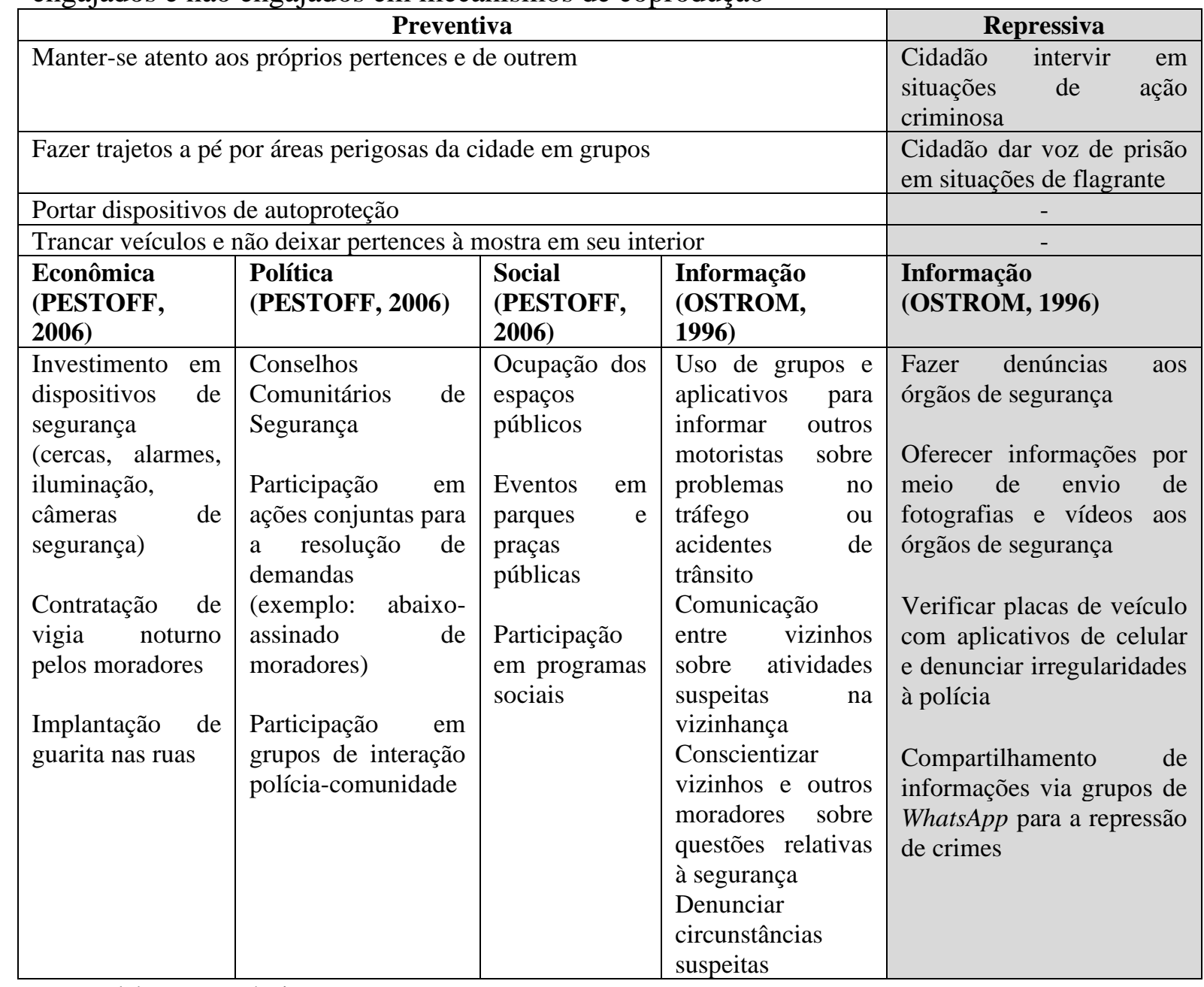

Fonte: elaboração própria. 
Ao decorrer das entrevistas foram sendo elencados exemplos de coprodução a partir das categorias delineadas previamente. Quanto à forma de coprodução preventiva, encontramse ações tanto individuais, tais como portar dispositivos de autoproteção e manter-se atento aos pertences, como grupais, como fazer trajetos em grupo por áreas perigosas (BRUDNEY; ENGLAND, 1983; PERCY, 1978). Quanto à categoria de coprodução econômica, observamse tanto esforços individuais como por meio de grupos de moradores. Foram citadas como exemplo de ações individuais o investimento em equipamentos de segurança para a própria residência, tal como a instalação de alarmes, dispositivos de iluminação e câmeras. Na coprodução econômica em grupos (BOVAIRD et al., 2015), verificou-se que os moradores se unem para dividir custos de implantação de guaritas de segurança na vizinhança e contratam segurança para realização de rondas na região.

Na categoria de coprodução política (PESTOFF, 2006), foram observados exemplos de coprodução relacionados à participação dos cidadãos nas reuniões dos Conselhos Comunitários que envolvem também a participação de membros dos órgãos de segurança pública, a participação em ações conjuntas, tais como abaixo-assinados ou manifestações necessárias para resolução de questões relacionadas à segurança, e por último, a participação em grupos de interação polícia-comunidade, em que foram citados programas dos órgãos de segurança para atender às demandas específicas da população de determinadas regiões.

No caso da segurança, a coprodução social (PESTOFF, 2006) foi a menos recorrente nas declarações dos entrevistados. Neste tipo de coprodução, que envolve participação e engajamento dos cidadãos em eventos relativos à prestação do serviço, ocorrendo por meio de ações grupais, foram identificados apenas três exemplos observáveis, sendo eles: a ocupação dos espaços públicos com vistas à redução do abandono de locais públicos e consequente aumento da possibilidade de ocorrência de desordens públicas; a participação em programas sociais que visam a integração entre os órgãos de segurança e a sociedade; e por último, a participação em eventos sobre prevenção de crimes e questões relativas à segurança pública.

No que diz respeito à coprodução repressiva, observaram-se exemplos de ações dos cidadãos para a repressão de crimes que não se encaixaram em nenhuma das categorias citadas anteriormente. Foram evidenciadas situações em que os cidadãos podem interferir utilizando-se de um poder que a própria lei lhes confere em situações de ações criminosas, como por exemplo, a possibilidade de prender outrem em situação de flagrante delito. De outro modo, a coprodução de informação, tanto repressiva como preventiva foi bastante enfatizada nas declarações dos entrevistados, sendo apresentada como uma das principais 
ações que os cidadãos reconhecem como forma de colaborar com a segurança pública, o que pode ser notado no seguinte trecho de fala:

Informação. Um vizinho cuida do outro, cuida da casa do outro. Se chega de tarde vê um movimento estranho, liga na casa do vizinho para saber se ele está bem, se vê um movimento e uma pessoa diferente liga para a polícia. É mesmo essa questão da informação. Um vizinho se preocupando com o outro porque se não for dessa forma, não vai (Entrevistado 3)

Assim, nota-se a relevância da interação e comunicação tanto entre os próprios cidadãos, como também entre os cidadãos e os órgãos de segurança, considerando que a coprodução de informação pode ocorrer tanto de forma preventiva, sendo mais ligada à questão da troca de informações entre os próprios vizinhos e também repressiva, ao denunciar eventuais situações de risco à segurança aos órgãos competentes.

$\mathrm{Na}$ forma preventiva, a coprodução de informação corresponde às ações de compartilhamento de informações para prevenção de crimes por meio de aplicativos de celular, uso de grupos e aplicativos para informar motoristas sobre problemas de trânsito, ações de conscientização de moradores sobre questões relativas à segurança na região. $\mathrm{Na}$ forma repressiva, a coprodução de informação consiste em ações como o oferecimento de informações aos órgãos de segurança para a repressão de crimes e a verificação da situação de placas de veículos suspeitos por meio de aplicativos de celular. Considerando-se a classificação proposta por Brudney e England (1983), a partir das declarações dos entrevistados, observa-se que a coprodução de informação preventiva se apresenta predominantemente por meio de atividades grupais, enquanto a coprodução de informação repressiva possui mais características da forma de coprodução individual.

\subsection{Propensão à coprodução da segurança}

Para identificar a propensão para coproduzir segurança, perguntou-se aos cidadãos não engajados em mecanismos formais de coprodução o que os tornaria mais dispostos a contribuir com a segurança da região em que residem. A saturação teórica ocorreu na nona entrevista. A partir de então, não houve mais novos enunciados em relação ao que tornaria os indivíduos mais dispostos a coproduzir. A partir da verificação da saturação teórica, o Quadro 10 apresenta as categorias encontradas e suas respectivas referências e descrições, além de trechos das declarações dos entrevistados que representam as categorias de análise. 
Quadro 10 - Aspectos que podem estimular a propensão do cidadão não engajado a coproduzir segurança

\begin{tabular}{|c|c|c|}
\hline Categorias & Descrição & Entrevistas: trechos das declarações \\
\hline \multirow{4}{*}{$\begin{array}{l}\text { Interação com o } \\
\text { provedor } \\
(\text { Etgar, 2008) }\end{array}$} & $\begin{array}{l}\text { Comunicação } \\
\text { eficiente com } \\
\text { órgãos de } \\
\text { segurança }\end{array}$ & $\begin{array}{l}\text { Eu acho que mais interação com o governo, eu acho que seria uma boa } \\
\text { ideia. O governo não tem esse contato com a gente, com a população } \\
\text { então dificulta muito para o governo saber qual a nossa opinião } \\
\text { (Entrevistado 15). }\end{array}$ \\
\hline & $\begin{array}{c}\text { Estímulo } \\
\text { governamental }\end{array}$ & $\begin{array}{l}\text { Talvez campanhas mais com o intuito de motivar e incentivar a } \\
\text { comunidade, o cidadão a registrar ocorrências por exemplo } \\
\text { (Entrevistado 11). }\end{array}$ \\
\hline & $\begin{array}{l}\text { Confiança nos } \\
\text { órgãos de } \\
\text { segurança }\end{array}$ & $\begin{array}{l}\text { A certeza de ser ouvido e de as demandas serem respondidas com } \\
\text { eficiência. Quando você não tem as respostas devidas, cai no } \\
\text { descrédito (Entrevistado 2). } \\
\text { Se parasse com tanta impunidade, aí eu sentiria mais vontade. Seria o } \\
\text { cumprimento das leis (Entrevistado } 41 \text { ). } \\
\text { Acredito que não ter medo, mas o pior que nós temos. Você vê, o } \\
\text { quanto que a gente se sente inseguro hoje (Entrevistado 29). }\end{array}$ \\
\hline & $\begin{array}{l}\text { Proximidade com } \\
\text { órgãos de } \\
\text { segurança }\end{array}$ & $\begin{array}{l}\text { A questão do posto policial que antes era bem próximo e inibia muito } \\
\text { a questão de roubo e assalto. Já hoje em dia até procurar uma } \\
\text { delegacia que é mais longe, eles estão em uma distância bem maior } \\
\text { (Entrevistado 42) }\end{array}$ \\
\hline $\begin{array}{l}\text { Nível de } \\
\text { satisfação com a } \\
\text { segurança } \\
\text { (Alford \& } \\
\text { Yates, 2015) }\end{array}$ & $\begin{array}{l}\text { Insatisfação com } \\
\text { a segurança } \\
\text { pública }\end{array}$ & $\begin{array}{l}\text { Acredito que a questão da insegurança, do que vem acontecendo lá. A } \\
\text { insatisfação com o serviço prestado pelo governo pode fazer com que } \\
\text { as pessoas atuem mais na segurança (Entrevistado 5) } \\
\text { Eu acho que as pessoas agem mais por necessidade, então se sentir } \\
\text { que está ficando mais perigoso as pessoas tendem a se mobilizar mais } \\
\text { (Entrevistado 17) } \\
\text { Ter mais índices de assaltos talvez, porque eu nunca sofri nada lá e } \\
\text { para mim é tranquilo (Entrevistado 46) }\end{array}$ \\
\hline Autodefesa & $\begin{array}{l}\text { Ampliação de } \\
\text { alternativas de } \\
\text { autodefesa do } \\
\text { cidadão }\end{array}$ & $\begin{array}{l}\text { Acredito que a possibilidade de portar armas, eu iria querer um } \\
\text { revólver. Porque aqui o governo não te dá armas para isso. Ou você } \\
\text { liga para a polícia e espera que eles façam alguma coisa, porque se } \\
\text { você fizer você é punido, então não têm armas para isso. Penso nessa } \\
\text { forma de a população poder se defender (Entrevistado 9). }\end{array}$ \\
\hline $\begin{array}{c}\text { Tempo } \\
\text { (Etgar, 2008) }\end{array}$ & $\begin{array}{l}\text { Tempo disponível } \\
\text { para engajamento }\end{array}$ & $\begin{array}{l}\text { Acho que se tivesse mais tempo, porque como a gente trabalha né, a } \\
\text { gente passa mais tempo fora e não sabe o que acontece enquanto a } \\
\text { gente está fora (Entrevistado } 36 \text { ). }\end{array}$ \\
\hline $\begin{array}{l}\text { Recursos } \\
\text { Financeiros } \\
\text { (Etgar, 2008) }\end{array}$ & $\begin{array}{l}\text { Recursos para } \\
\text { investimento em } \\
\text { autoproteção }\end{array}$ & $\begin{array}{l}\text { Acho que a questão de ter mais dinheiro, mais recurso porque os } \\
\text { equipamentos são caros também, né (Entrevistado 25). } \\
\text { Acho que se tivesse mais tempo e dinheiro para poder investir nisso } \\
\text { (Entrevistado } 30 \text { ) }\end{array}$ \\
\hline $\begin{array}{l}\text { Formas de } \\
\text { participação } \\
\text { (Etgar, 2008; } \\
\text { Sunstein \& } \\
\text { Thaler, 2008) }\end{array}$ & $\begin{array}{l}\text { Conhecimento } \\
\text { sobre meios de } \\
\text { participação }\end{array}$ & $\begin{array}{l}\text { Se tivesse mais divulgação e a gente ficasse sabendo, eu acho que teria } \\
\text { como a gente contribuir (Entrevistado 10). } \\
\text { Eu acho que se houvesse mais divulgação dos meios de participação } \\
\text { que já existem ou uma melhoria do sistema de participação da } \\
\text { população, aí teria como as pessoas se envolverem e colaborarem } \\
\text { nesse sentido (Entrevistado 13). }\end{array}$ \\
\hline $\begin{array}{l}\text { Mobilização } \\
\text { coletiva } \\
\text { (Brudney \& } \\
\text { England, 1983) }\end{array}$ & $\begin{array}{l}\text { Atuação conjunta } \\
\text { dos cidadãos para } \\
\text { colaborar com a } \\
\text { segurança }\end{array}$ & $\begin{array}{l}\text { Eu acho que a princípio, uma pessoa só não adianta. É aquele ditado, } \\
\text { uma andorinha só não faz verão. Acho que eu não teria como } \\
\text { colaborar sozinha, mas se fosse uma ação coletiva, dinamismo, todo } \\
\text { mundo em prol de um objetivo em comum, aí traria resultados } \\
\text { (Entrevistado 10). }\end{array}$ \\
\hline
\end{tabular}

Fonte: elaboração própria.

Ao propor um modelo para descrever os estágios de envolvimento dos cidadãos na coprodução de serviços, Etgar (2008) enfatizou que inicialmente ocorre o desenvolvimento de 
condições antecedentes. Dentre as categorias de propensão à coprodução identificadas e que se relacionam com o desenvolvimento de condições antecedentes, observam-se a interação com o provedor e o conhecimento sobre formas de participação, que estão ligadas aos fatores situacionais (ETGAR, 2008). No que diz respeito à interação com o provedor, foram relatados a comunicação eficiente com o governo, os estímulos governamentais, a confiança nos órgãos de segurança e a proximidade entre cidadãos e governo. Quanto ao conhecimento sobre formas de participação, Sunstein e Thaler (2008) evidenciam que este fator é determinante para que os indivíduos possam reconhecer os mecanismos e estímulos para tomar a decisão de participar. Ainda no que diz respeito às condições antecedentes, verificam-se fatores relacionados ao usuário, como por exemplo, o tempo e recursos disponíveis para o engajamento em ações de coprodução (ETGAR, 2008), citados como fatores que tornariam os cidadãos não engajados mais propensos a colaborar com a segurança pública. No que diz respeito ao tempo disponível, grande parte dos entrevistados que residem em regiões mais distantes da região central da cidade evidenciou que está a maior parte do tempo distante de sua residência, o que dificulta a participação e o envolvimento em atividades de coprodução.

Outra categoria que emergiu das entrevistas com os cidadãos foi a de autodefesa. Alguns entrevistados evidenciaram que se sentiriam mais propensos a coproduzir no caso de possuírem maior possibilidade de autodefesa, especialmente utilizando-se de dispositivos de autoproteção, como por exemplo, armas de fogo. A nova política do governo federal, que diz respeito à facilitação da aquisição e posse de armas de fogo implementada por meio do decreto n. 9685 de 2019 pode ser vista como uma forma de ampliação da possibilidade de autoproteção dos cidadãos, entretanto devem-se considerar as controvérsias da implementação deste instrumento. Em um país cujos índices de criminalidade são considerados alarmantes e consideravelmente ligados ao uso de armas de fogo (IPEA, 2018), a facilitação do acesso às armas pode ser uma medida que caminha em direção contrária à proposta de autoproteção, uma vez que pode ocasionar circunstâncias de uso indevido do armamento e situações de perigo que coloquem em risco a segurança pública. É importante salientar que existem outras formas de autoproteção corporal/individual além das armas de fogo, com considerável eficácia e baixo poder de letalidade, tal como o uso de spray de pimenta e armas de eletrochoque. Porém, questiona-se quão adequado e producente seria permitir o acesso a armas não letais à população para que esta se responsabilize por sua própria defesa.

Para Bitner et al. (1997), em algumas circunstâncias os usuários podem atuar como substitutos do prestador de serviços, sendo que para alguns autores, a terceirização e a 
transferência da responsabilidade pela prestação do serviço para o usuário não seriam vistas como uma forma de coprodução. Muito provavelmente esse tipo de estratégia poderia ser considerado como uma forma de autosserviço, um self-service em área tão sensível como a proteção da vida e do ambiente em que se vive. Ademais, o país apresenta, ainda, mais preocupação com a repressão do que com a educação e desenvolvimento de cidadãos esclarecidos e menos propensos à violência. Ao se considerar uma mudança nessa realidade pensando-se em ações duradouras e de longo prazo, a educação e políticas sociais unidas a outras ações, ainda parecem ser o melhor antídoto à escalada de violência verificada no Brasil (CASTRO; LEITE, 2006).

Outro aspecto citado pelos entrevistados diz respeito ao nível de satisfação com a segurança (ALFORD; YATES, 2015), em que alguns cidadãos demonstraram que estariam mais propensos a coproduzir no caso de se sentirem insatisfeitos com o serviço prestado pelo governo e no caso de perceberem um aumento nos índices de criminalidade ou situações que considerem alarmantes. Segundo Alford e Yates (2015) o efeito do nível de satisfação com a prestação do serviço pelo provedor sobre a propensão ainda não é um consenso, existindo situações em que os indivíduos se sentiriam mais propensos a coproduzir no caso de perceberem positivamente a performance do governo na entrega do serviço. Os entrevistados também declararam que se sentiriam mais propensos a participar em ações de segurança caso houvesse maior mobilização coletiva (BRUDNEY; ENGLAND, 1983), em que fossem criados grupos para interação dos moradores e vizinhos para a solução de demandas relacionadas à segurança pública. Esta constatação mostra-se contrária à ideia de que os indivíduos estariam mais dispostos a colaborar por meio de ações individuais e com pouca interação com outros indivíduos (ALFORD; YATES, 2015), trazendo uma reflexão sobre a propensão a coproduzir e as formas pelas quais os cidadãos desempenham as atividades de coprodução.

\section{CONSIDERAÇÕES FINAIS}

O presente estudo teve como objetivo analisar de que modo ocorre a coprodução da segurança pública considerando as atividades de coprodução as formas de envolvimento e a propensão do cidadão para coproduzir segurança no Distrito Federal. Com o intuito de se aproximar do fenômeno estudado e alcançar o objetivo geral, foram delineados e atingidos os objetivos específicos traçados para o estudo. Foram identificadas atividades de coprodução 
em todas as etapas da prestação do serviço (NABATCHI; SANCINO; SICILIA, 2017), sendo observados exemplos de co-comissioning na interação entre os órgãos de segurança e os cidadãos para definição das demandas prioritárias de segurança nas regiões; de co-designing quando órgãos de segurança atuam em conjunto com cidadãos engajados para o desenvolvimento de aplicativos que contribuam para a segurança pública; de co-delivery quando os cidadãos se organizam para conscientizar outros moradores, por exemplo, por meio do oferecimento de cursos com o objetivo de melhorar a segurança da região, bem como fornecendo e solicitando assistência aos órgãos de segurança; e de co-assessment quando os cidadãos oferecem informações, sugestões e críticas sobre segurança ao governo por meio de ouvidorias e sites governamentais.

Foram observadas duas formas principais de coprodução da segurança pública, que foram categorizadas a posteriori, no processo de análise de conteúdo, contemplando as demais formas de coprodução de segurança, sendo elas as formas de coprodução preventiva e repressiva. Nesse sentido, os esforços de coprodução de segurança apontados pelos cidadãos na exposição das atividades desenvolvidas foram analisados a partir de sua natureza de prevenção ou repressão, considerando o tipo de contribuição da ação para a manutenção da segurança pública.

$\mathrm{Na}$ categoria que envolve ações de natureza preventiva, além daquelas enquadradas puramente como ações preventivas, tal como portar dispositivos de autoproteção, observaramse também as formas de coprodução econômica, política, social e de informação, manifestadas por meio de ações como investimento em câmeras de segurança e alarmes, participação em reuniões dos Conselhos Comunitários de Segurança, ocupação do espaço público e a denúncia de situações suspeitas à polícia para a prevenção da ocorrência de crimes.

Quanto à categoria que abrange ações de natureza repressiva, foram identificadas ações puramente voltadas para a repressão de crimes, como ocasiões em que o cidadão pode intervir em situações de ação criminosa e dar voz de prisão a outro cidadão em situação de flagrante, e também, identificou-se a coprodução de informação, por meio de ações como o oferecimento de informações que auxiliem a repressão de crimes pela polícia.

Nesse sentido, as evidências encontradas permitem uma melhor compreensão das atividades de coprodução que os cidadãos reconhecem como ações para contribuir com a segurança pública e ampliam as formas de coprodução encontradas na literatura. O estudo traz 
um olhar sobre a natureza da contribuição da ação do cidadão para a segurança, considerando as formas de coprodução preventiva e repressiva, além daquelas exploradas por Pestoff (2006) - econômica, política e social - bem como a coprodução de informação (OSTROM, 1996), que pode ocorrer tanto por meio da interação do cidadão com os órgãos de segurança pública, como entre os próprios cidadãos, visando a prevenção ou repressão de situações de risco à segurança pública.

No que se refere aos aspectos que podem estimular a propensão do cidadão a coproduzir segurança, extraíram-se da análise de conteúdo das entrevistas sete categorias que poderiam tornar os cidadãos não engajados mais dispostos a contribuir, sendo eles: a interação com o governo, considerando a comunicação com os órgãos de segurança, o estímulo governamental, a confiança nos órgãos de segurança e a proximidade com os mesmos; o nível de satisfação com a prestação do serviço público; a possibilidade de autodefesa; tempo e recursos disponíveis; o conhecimento sobre as formas de participação; e por último, a mobilização coletiva. Desses sete fatores, a literatura revisada já trazia a interação com o governo (ETGAR, 2008), o nível de satisfação com a prestação do serviço (ALFORD; YATES, 2015), tempo e recurso disponíveis (ETGAR, 2008), o conhecimento sobre formas de participação (SUNSTEIN; THALER, 2008) e a mobilização coletiva (BRUDNEY; ENGLAND, 1983). O estudo trouxe outro aspecto, denominado a posteriori como a ampliação da possibilidade de autodefesa do cidadão.

Desse modo, o presente trabalho traz uma contribuição no sentido de aprofundar as investigações sobre coprodução de serviços públicos no país, especialmente no que diz respeito à segurança pública, aspecto em que diverge consideravelmente da realidade de outros países, considerando os diferentes níveis de desenvolvimento e índices de criminalidade. Nesse sentido, o esforço exploratório e descritivo do estudo possibilitou um maior entendimento sobre como se dá a coprodução da segurança pública a partir de suas diferentes formas, expandindo a compreensão sobre o fenômeno em análise. Pesquisas futuras de amplo alcance, como surveys, poderiam analisar a relação entre diversas variáveis, tais como as formas de coprodução de segurança encontradas e o perfil dos indivíduos coprodutores, bem como a relação entre o perfil dos cidadãos e os aspectos que os tornariam mais propensos a coproduzir segurança pública. 


\section{REFERÊNCIAS}

ALFORD, J.; YATES, S. Co-Production of public services in Australia: The roles of government organisations and Co-Producers. Australian Journal of Public Administration, v. 75, n. 2 , p. $159-175,2016$.

BARDIN, L. Análise de conteúdo. Tradução Luís Antero Reto. Augusto. Pinheiro. Ed, 70, 125-198, 2016.

BITNER, M. et al. Customer contributions and roles in service delivery. International journal of service industry management, v. 8, n. 3, p. 193-205, 1997.

BOVAIRD, T. Beyond engagement and participation: User and community coproduction of public services. Public administration review, v. 67, n. 5, p. 846-860, 2007.

BOVAIRD, T. et al. Activating collective co-production of public services: influencing citizens to participate in complex governance mechanisms in the UK. International Review of Administrative Sciences, v. 82, n. 1, p. 47-68, 2016.

BOVAIRD, T.; LOEFFLER, E. From engagement to co-production: The contribution of users and communities to outcomes and public value. Voluntas: International Journal of Voluntary and Nonprofit Organizations, v. 23, n. 4, p. 1119-1138, 2012.

BOVAIRD, T.; LOEFFLER, E. User and community co-production of public services: What does the evidence tell us? International Journal of Public Administration, v. 39, n. 13, p. 1006-1019, 2016.

BOYLE, D.; HARRIS, M. The challenge of co-production. London: new economics foundation, 2009.

BRASIL. Constituição da república federativa do Brasil. Brasília: Senado Federal, Centro Gráfico, 1988.

BRUDNEY, J. L.; ENGLAND, R. E. Toward a definition of the coproduction concept. Public administration review, p. 59-65, 1983.

CARVALHO, V. A; SILVA, M.R. Política de segurança pública no Brasil: avanços, limites e desafios. Revista Katálysis, v. 14, n. 1, p. 59-67, 2011. 
CASTRO, M. H. M.; LEITE, E. M. Educação no Brasil: atrasos, conquistas e desafios. In: Brasil o estado de uma nação. Brasília: IPEA, 2006.

CRESWELL, J. W. Projeto de pesquisa métodos qualitativo, quantitativo e misto. 03. Ed. Porto Alegre: Artmed, 2010.

DISTRITO FEDERAL. Lei Orgânica do Distrito Federal. Disponível em <http://www2.senado.leg.br/bdsf/handle/id/70442>. 2019.

DISTRITO FEDERAL. Balanço da segurança. Estatísticas criminais. Disponível em <http://www.ssp.df.gov.br/images/SGI/janeiro_2018_final.pdf>. 2018.

ETGAR, M. A descriptive model of the consumer co-production process. Journal of the academy of marketing science, v. 36, n. 1, p. 97-108, 2008.

FALQUETO, J.; FARIAS, J. Saturação teórica em pesquisas qualitativas: relato de uma experiência de aplicação em estudo na área de administração. In: $5^{\circ}$ Congresso IberoAmericano Em Investigação Qualitativa. 2016. p. 560-569.

GERSUNY, C.; ROSENGREN, W. R. The service society. Schenkman Publishing Company, 1973.

GIL, A. C. Como elaborar projetos de pesquisa. São Paulo, v. 5, n. 61, p. 16-17, 2002.

INSTITUTO DE PESQUISA ECONÔMICA APLICADA. Atlas da Violência. Disponível em:

<http://www.ipea.gov.br/portal/images/stories/PDFs/relatorio_institucional/180604_atlas_da_ violencia_2018.pdf>. Acesso em: $23 \mathrm{dez} .2018$.

LEVINE, C. H.; FISHER, G. Citizenship and service delivery: The promise of coproduction. Public Administration Review, v. 44, p. 178-189, 1984.

LOEFFLER, E. et al. If you want to go fast, walk alone. If you want to go far, walk together. Citizens and the co-production of public services. Budget and Public Services, Paris, 2008.

LUSCH, R. F.; VARGO, S. L. Service-dominant logic: reactions, reflections and refinements. Marketing theory, v. 6, n. 3, p. 281-288, 2006. 
MATTIA, C.; ZAPPELLINI, M. B. Ética e coprodução de serviços públicos: uma fundamentação a partir de Habermas. Cadernos EBAPE. BR, v. 12, n. 3, p. 573-589, 2014.

MINAYO, M. C. S. Amostragem e saturação em pesquisa qualitativa: consensos e controvérsias. Revista Pesquisa Qualitativa, v. 5, n. 7, p. 1-12, 2017.

NABATCHI, T.; SANCINO, A.; SICILIA, M. Varieties of participation in public services: The who, when, and what of coproduction. Public Administration Review, v. 77, n. 5, p. 766-776, 2017.

OSBORNE, D.; GAEBLER, T. Reinventando o governo: como o espírito empreendedor está transformando o setor público. Mh Comunicação, 1992.

OSTROM, E. Crossing the great divide: coproduction, synergy, and development. World development, v. 24, n. 6, p. 1073-1087, 1996.

OSTROM, E. et al. The public service production process: a framework for analyzing police services. Policy Studies Journal, v. 7, p. 381, 1978.

OSTROM, V.; OSTROM, E. Public goods and public choices. In: Polycentricity and local public economies. Readings from the workshop in political theory and policy analysis. Ann Arbor, MI, USA: University of Michigan Press, p. 75-105, 1999.

PARKS, R. B. et al. Consumers as coproducers of public services: Some economic and institutional considerations. Policy Studies Journal, v. 9, n. 7, p. 1001-1011, 1981.

PERCY, Stephen L. Conceptualizing and measuring citizen co-production of community safety. Policy Studies Journal, v. 7, p. 486, 1978.

PESTOFF, V. Citizens and co-production of welfare services: Childcare in eight European countries. Public management review, v. 8, n. 4, p. 503-519, 2006.

RICH, R. C. Interaction of the voluntary and governmental sectors: Toward an understanding of the coproduction of municipal services. Administration \& Society, v. 13, n. 1, p. 59-76, 1981.

ROSENTRAUB, M. S., \& Sharp, E. B. Consumers and producers of social services: Coproduction and the level of social services. Southern Review of Public Administration, v. 4, n. 4 , p. 502-539, 1981. 
SALM, J. F.; MENEGASSO, M. E. Proposta de modelos para a coprodução do bem público a partir das tipologias de participação. XXXIV ENCONTRO DA ANPAD. Anais... Rio de Janeiro, 2010.

SCHNEIDER, A. L. Coproduction of Public and Private Safety: An Analysis of Bystander Intervention, 'Protective Neighboring,' and Personal Protection. Western Political Quarterly, v. 40, n. 4, p. 611-630, 1987.

SUNSTEIN, C. R; THALER, R. H.; Nudge: Improving decisions about health, wealth, and happiness. Penguin, 2009.

THIRY-CHERQUES, H. R. Saturação em pesquisa qualitativa: estimativa empírica de dimensionamento. Revista PMKT, v. 3, n. 2, p. 20-27, 2009.

VERSCHUERE, B.; BRANDSEN, T.; PESTOFF, V. Co-production: The state of the art in research and the future agenda. Voluntas: International Journal of Voluntary and Nonprofit Organizations, v. 23, n. 4, p. 1083-1101, 2012.

VINUTO, J. A amostragem em bola de neve na pesquisa qualitativa: um debate em aberto. Temáticas, n. 44, 2016.

WILLIAMS, B. N. et al. The co-production of campus safety and security: a case study at the University of Georgia. International Review of Administrative Sciences, v. 82, n. 1, p. 110130, 2016.

WHITAKER, G. P. Coproduction: Citizen participation in service delivery. Public administration review, p. 240-246, 1980. 